\section{EDUCAÇÃO}

V.8・N.3 2020 - Fluxo Contínuo

ISSN Digital: 2316-3828

ISSN Impresso: 2316-333X

DOI: 10.17564/2316-3828.2020v8n3p322-334
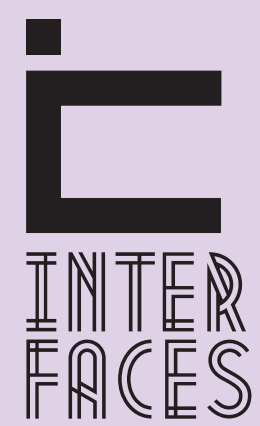

CIENTÍFICAS

\title{
A IMAGEM DIGITAL NO CIBERESPAÇO: SENTIDOS E APROPRIAÇ̃̃ES EM ITINERÁRIOS DE APRENDIZAGEM
}

\section{LA IMAGEN DIGITAL EN EL CIBERESPACIO: SENTIDOS Y APROPIACIÓN EN ITINERARIOS DE APRENDIZAJE}

DIGITAL IMAGE IN CYBERESPACE: SENSES AND APPROPRIATIONS IN LEARNING ITINERARIES

\section{RESUMO}

Este trabalho busca apresentar algumas reflexões acerca da importância da imagem digital no ciberespaço e os caminhos interpretativos que ela fornece, trazendo consigo sentidos e apropriações peculiares e diversificados que a torna exponencial não somente em situações específicas, mas em todos os lugares que compõem os espaços contemporâneos de atuação, inclusive no contexto escolar. As tecnologias digitais da informação e da comunicação (TDIC) se configuram como o grande condutor para a disseminação de imagens pelas redes, tornando o processo de transmissão cada vez mais rápido, volátil e mutante. Dessa maneira, a escola se vê pressionada a repensar a sua real função, visto que as TDIC precisam se tornar um fundamento prático na realidade escolar. Para evidenciar o uso da imagem digital nos trabalhos desenvolvidos na escola, trazemos um recorte de um trabalho interventivo por meio de um relato de experiência que descreve a itinerância de alguns professores de língua inglesa da cidade de Serrolândia-BA (Brasil) acerca do uso da imagem digital em suas mais variadas formas de composição, tais como fotografia, vídeo, stop motion, dentre outros, a fim de percebermos como este recurso pode se tornar um grande aliado nos processos de aprendizagem, o que resultou em novas percepções pedagógicas e novos caminhos de significação que a imagem digital pode fornecer. Para tanto, utilizamos de uma pesquisa bibliográfica, bem como apresentamos os passos colaborativos e temáticas seguidas pelos professores-cursistas para chegarem aos objetivos traçados pelo grupo. Pudemos perceber as significativas ramificações interpretativas que podem surgir a partir do uso crítico da imagem no contexto educacional e, para além disso, compreender a importância desse re- 
curso na prática pedagógica, vinculado aos dispositivos eletrônicos digitais existentes hoje que o tornam ainda mais presente e mutável em nosso dia a dia.

\section{PALAVRAS-CHAVE}

Imagem Digital. Tecnologias Digitais da Informação e da Comunicação. Ciberespaço. Educação.

\section{RESUMEN}

Este estudio tiene como objetivo presentar algunas reflexiones sobre la importancia de la imagen digital en el ciberespacio y caminos interpretativos que ofrece, con lo que los significados y créditos que lo hace exponencialmente no solo en situaciones específicas únicas y diversas, pero en todas partes que conforman los espacios contemporáneos de trabajo, incluso en el contexto escolar. Las tecnologías digitales de la información y la comunicación (TDIC) se configuran como el gran impulsor de la difusión de imágenes a través de redes, haciendo que el proceso de transferencia más rápida, volátil y cambiante. De esta manera, la escuela se ve presionada a replantearse su función real, ya que las TDIC necesitan convertirse en una base práctica en la realidad escolar. Para demostrar el uso de la imagen digital en el trabajo realizado en la escuela, presentamos un recorte de un trabajo intervencionista a través de un informe que describe las experiencias itinerantes de algunos profesores de inglés en la ciudad de Serrolândia, Bahia (Brasil) en el uso de imagen digital en sus diversas formas de composición, como la fotografía, el video, stop motion, entre otros, con el fin de darse cuenta de cómo esta función puede llegar a ser un gran aliado en los procesos de aprendizaje, dando lugar a nuevos conocimientos pedagógicos y nuevas formas de significado que la imagen digital puede ofrecer. Por lo tanto, utilizamos una búsqueda en la literatura y presentamos los pasos de colaboración y temáticos seguidos de los maestros para alcanzar los objetivos fijados por el grupo. Nos dimos cuenta de ramificaciones significativas interpretativas que puedan derivarse de la utilización crítica de la imagen en el contexto educativo y, por otra parte, entendimos la importancia de este recurso en la enseñanza de la práctica, ligada a los dispositivos electrónicos digitales existentes en la actualidad que lo hacen aún más presente y cambiante en nuestro día a día.

\section{PALABRAS CLAVE}

Imágenes Digitales; Las tecnologías digitales de información y comunicación; ciberespacio; Educación.

\section{ABSTRACT}

This paper presents some reflections about the importance of digital imagine in cyberspace and the interpretative paths it provides, bringing with it peculiar and diversified senses and appropriations that make it exponential not only in specific situations but in all places that compose contemporary 
spaces including the school context. Digital information and communication technologies (DICT) are the main drivers for the dissemination of images through networks, making the transmission process increasingly fast, volatile and mutant. In this way, the school is under pressure to rethink its real function, since the DICTS need to become a practical foundation in the school reality. In order to highlight the use of the digital image in works developed in the school, we bring a part of an intervention work through an experience report that describes the itinerancy of some English teachers of the city of Serrolândia, BA (Brazil) about the use of the digital image in its most varied forms of composition, such as photography, video, stop motion, among others, in order to realize how this resource can become a great ally in the learning processes, which resulted in new pedagogical perceptions and new paths of meaning that the digital image can provide. To do so, we used a bibliographical research, as well as presenting the collaborative and thematic steps followed by the teachers to reach the objectives outlined by the group. We could perceive the significant interpretive ramifications that can arise from the critical use of the image in the educational context and, in addition, understand the importance of this resource in pedagogical practice, linked to the digital electronic devices existing nowadays that make it even more present and changeable in our life.

\section{KEYWORDS}

Digital Image. Digital Information and Communication Technologies. Cyberspace. Education.

\section{INTRODUÇ̧̃̃O}

A era digital tem proporcionado por meio dos seus artefatos tecnológicos móveis, formas outras de ensinar, aprender, comunicar, ler e se relacionar, tais dispositivos provocam mutações profundas nas atividades humanas, impactam os fazeres cotidianos e faz com que nós ou o que produzimos 'vagueie' no ciberespaço de forma fluída, nômade, ubíqua ao sabor de um simples toque em uma tela de silício.

Toda essa mobilidade oportuniza invenções, reordenamentos, sobreposições, mixagens, bricolagens que impactam diretamente na nossa forma de "ver", "ler" e "compreender" o mundo. Com a ascensão das tecnologias digitais da informação e da comunicação (TDIC), a imagem digital multiplicou-se exponencialmente, principalmente pela popularização das câmeras digitais embutidas nos smartphones. $\mathrm{O}$ ato de fotografar antes restrito a momentos "posados" e mágicos, agora se tornou trivial e alcançou o status de instantes efêmeros que podem ser manipulados pixel a pixel ou apagados se não houver satisfação na imagem.

A imagem digital é volátil, compartilhável, fotografa-se momentos sem nenhum ou com alto grau de significância, está imersa no ciberespaço e se propaga infinitamente, reproduzindo "verdades" e discursos, assim acreditamos que com toda essa complexidade, a discussão e reflexão sobre a imagem digital precisa se fazer presente nos espaços formais de aprendizagem, já que estes figuram como lócus de representação da cultura contemporânea. 
Neste artigo objetivamos apresentar algumas reflexões acerca da importância da imagem digital no ciberespaço e os caminhos interpretativos que ela fornece, a partir do recorte de um trabalho interventivo por meio de relato de experiência com professores de língua inglesa da cidade de Serrolândia-BA (Brasil), que utilizaram fotografia, vídeo, stop motion, dentre outros recursos que coexistem no meio digital.

A partir do trabalho desenvolvido perceberemos que a imagem digital precisa ser incluída no contexto educativo de forma crítica, para que a compreensão acerca da imagem seja alargada, observando a disseminação de valores, as ideologias que são propagadas, "os novos regimes do sentir e do saber” (GOMES; SILVA, 2014, p. 3), objetivando a formação de sujeitos ativos, críticos que tenham a percepção de si e do mundo mutável que o cerca.

\section{VIVÊNCIAS MÓVEIS NO CIBERESPAÇO: A FLUIDEZ DA IMAGEM DIGITAL}

Mexer-se não é mais deslocar-se de um ponto a outro da superfície terrestre, mas atravessar universos de problemas, mundo vividos, paisagens dos sentidos. Essas derivas nas texturas da humanidade podem recortar as trajetórias balizadas dos circuitos de comunicação e de transporte, mas as navegações transversais, heterogêneas dos novos nômades, exploram outro espaço. Somos imigrantes da subjetividade. (LÈVY, 2014, p. 14).

Os dispositivos móveis conectados à rede de internet têm provocado deslocamentos em diversos aspectos das atividades humanas. Com a digitalização e virtualização dos dados, textos, imagens e sons, a comunicação tem-se diversificado e difundido crescentemente, tal desenvolvimento inscreve-se em uma mutação de grande alcance, que é impulsionada pelos novos artefatos culturais, mas que os ultrapassa, "voltamos a ser nômades" (LÈVY, 2014, p. 15).

Tais artefatos, como os celulares, possibilitam ao seu usuário "desplugar-se" dos computadores fixos para experienciar-se em uma conexão desterritorializada, por isso nômade e ubíqua. 0 nomadismo aqui se refere a viagens imóveis, proporcionadas pelas transformações várias do mundo que nos circunda, saímos da imobilidade frente às televisões e computadores e "vagueamos" nesse espaço invisível de conhecimentos, saberes, potências de pensamento em que brotam, transformam as qualidades do ser e as maneiras de se constituir em sociedade.

Fundam-se assim novas maneiras de pensar, conviver, aprender e ser, como nos fala Pierre Lèvy (2014, p. 16):

Massas de refugiados em marcha para campos improváveis... Nações sem domicílio fixo... Epidemias de guerras civis... Barulhentas "babéis", megalópoles mundiais... Travessia de saberes da sobrevida nos interstícios do império... Impossível fundar uma cidade, impossível doravante estabelecer-se em qualquer lugar que seja, num segredo, num poder, num solo... Os signos, por sua vez, tornam-se migrantes: esse húmus não para de tremer, de arder... Deslizamentos vertiginosos entre as religiões e as línguas entre as vozes e os cantos, e bruscamente, na esquina de um corredor subterrâneo, surge a música do futuro... A Terra como uma bola sob o olho gigante de um satélite [...]. 
Nesta representação do mundo, o ciberespaço, que mais parece cenário de ficção científica, o autor traça um panorama da era da informação, da comunicação, da mobilidade, do fluxo, das trocas e agenciamentos culturais. Nesse ínterim, arquiteta-se de maneira líquida e camaleônica a cibercultura. Esta inscreve-se em nosso dia a dia, nas mais diversas atividades, nos campos do trabalho, familiar, lazer e vida privada, para André Lemos (2013) é uma sinergia entre a vida social, os dispositivos eletrônicos e suas redes telemáticas.

A cibercultura nasceu em 1950 com a informática e cibernética, torna-se popular em 1970 quando surge o computador e estabelece-se a partir das décadas de 1980 e 1990, com a informática de massa e com o advento da internet (LEMOS, 2013).

Para Donald Peterson (apud SANTAELLA, 2007), a cibercultura divide-se em quatro fases: a primeira é a do hardware básico, dos computadores fixos, a segunda é a fase dos softwares, a terceira é a das interfaces gráficas, a quarta é a fase das redes, com a www que oportunizou habitarmos uma nova ecologia e avançarmos para a fase cinco que ele conceitua como fase ecológica. Nesta fase, que é a da revolução informacional ou a da "net-condição que, segundo Peterson, exige que a informação seja por nós filtrada, administrada e manipulada para que ela se transforme em conhecimento" (SANTAELLA, 2007, p. 20), há a renovação do ciclo cultural, numa trama hipercomplexa e híbrida e não a sobreposição dos ciclos anteriores.

Para alcançarmos essa net-condição, Pierre Lèvy (2014) vislumbra o engajamento coletivo na tentativa de inventar técnicas, pensar em conjunto, convergir esforços intelectuais, pluralizar nossas imaginações e experiências a fim de dar soluções práticas aos complexos problemas que estão diante de nós.

Quanto melhor os grupos humanos conseguem se constituir em coletivos inteligentes, em sujeitos cognitivos, abertos, capazes de iniciativa, de imaginação e de reação rápidas, melhor asseguram seu sucesso no ambiente altamente competitivo que é o nosso. (LĖVY, 2014, p. 19).

A concepção defendida pelo autor é de inteligência em massa, uma inteligência distribuída ininterruptamente, em espaços vários, articulada em tempo real, que será resultado de uma motivação bem-sucedida das competências. Nesse axioma, os humanos não agiriam "bestializados" ou "manipulados", mas estariam interagindo em diversas comunidades, como "seres singulares, múltiplos, nômades e em vias de metamorfose (ou de aprendizado) permanente” (LĖVY, 2014, p. 32).

Para tanto, as tecnologias digitais da informação e da comunicação (TDIC) são vistas como o ingresso para o espaço do saber. Nesse novo espaço antropológico, visto que estão distribuídas por toda parte, para Lèvy (2014, p. 55) “o digital é móvel, passível de reordenamento, mixagens e combinações”, por meio destes aparatos, a humanidade pode produzir ferramentas que permitirão constituir-se em coletivos inteligentes e se orientar entre os mares tempestuosos da mutação.

Para além dos suportes fixos, estáveis, o hipertexto digital proporciona e possibilita pequenas "invenções" que são engendradas bit por bit, atendem a circunstâncias diversas e são feitas por meio de uma espécie de bricolagem4 que instauram modos de ser e de viver.

$4 \mathrm{O}$ termo bricolagem ou bricolage/bricolagem vem do francês bricolage, é usado nas atividades em que você mesmo realiza para seu próprio uso ou consumo, evitando deste modo, o emprego de um serviço profissional. Disponível em: http://pt.wikipedia.org/wiki/Bricolagem 
Nesse espírito inventivo a imagem digital tem causado significativas mudanças, por ser virtual, editável, tornou-se mais popular e qualquer pessoa com habilidades mínimas pode ser fotógrafo de um descartável instante, pois se destaca o registro da espontaneidade do momento.

O instante, que na fotografia já é banalizado, com a digitalização passa a ser também descartável e reconstruível. Se a foto não fica boa, é só deletar e fazer outra, sem a necessidade de esperar a revelação. 0 instante se revela automaticamente, instantaneamente, em tempo real, numa pequena tela de cristal líquido (AGUIAR, 2006,p. 40).

Com essa mobilidade, onde as imagens podem ser engendradas a cada pixel que metamorfoseia a imagem em números, por meio de softwares simples pode-se recriá-la, transmutando-a, convertendo-a, simulando-a ao sabor da representação do real. Quéau (2003) conceitua essas imagens como imagens síntese ou simulações do real porque não recriam instantes mágicos, mas sim são programáveis, numéricas, materializáveis em interfaces.

Santaella e Nöth (1997) situam a imagem digital no paradigma pós-fotográfico porque ela proporciona um corte, uma forte modificação no status da imagem na contemporaneidade, tanto é que para Quéau (2003) ela "constitui uma nova forma de escrita que modificará profundamente nossos métodos de representação, nossos hábitos visuais, nossos modos de trabalhar e criar” (QUÉAU, 2003, p. 91).

Nessa complexidade da imagem digital, com todas as suas flutuações e fluxos, ela torna-se interativa, condutora de diversas mensagens culturais, em interfaces variadas. Para Catalá (2010, p. 143):

$\mathrm{Na}$ interface, o conhecimento é imagem, as ideias adquirem forma visual. Na interface, a razão se impõe sobre o ser e o subjetiva. No entanto, por sua vez, a imagem deixa de estar frente a nós e o sujeito deixa de ser um agente distante que atua por osmose, por absorção das coisas em sua pura subjetividade. Pelo contrário, o sujeito se incorpora na própria imagem do conhecimento que resulta da fusão de si mesmo com a representação subjetivada. 0 sujeito se torna objeto e o objeto, sujeito, em um contínuo dobrar-se e redobrar-se.

Assim, a representação hibridiza-se, estende-se para vários locais, virtualizando-se em múltiplos espaços potenciais nos quais a imagem é dominante e propagadora de estética, comunicação e conhecimento.

Essa mutação antropológica contemporânea é uma nova forma de ser humano que supera a dicotomia real/virtual, o que somos e o que fazemos no ciberespaço não deixa de refletir, influenciar ou modificar a nossa constituição. Assim, Lemos (2013) conclui que as tecnologias são prolongamentos do nosso corpo, próteses dos novos sentidos, "são a extensão do nosso sistema nervoso central" (LEMOS, 2013, p. 70). Para o autor a cada tecnologia incorporada e invisibilizada no nosso cotidiano tornamo-nos menos criaturas de carne, osso e sangue para metamorfosear-nos em criaturas de espírito-zapping, bits e bytes, movendo-nos na velocidade da luz.

Tal concepção é oriunda do “Manifesto Ciborgue”, de autoria da feminista Donna Haraway, um ensaio publicado nos anos 1980, nos Estados Unidos que é amplamente difundido na literatura con- 
temporânea por trazer problematizações acerca do pensamento contemporâneo sobre subjetividade, tecnologia, ciência, gênero e sexualidade (HARAWAY, 2013).

Para a autora, em virtude da nossa íntima e imbricada relação com a tecnologia, não é mais possível dizer onde acaba o humano e onde começa a máquina. Nesta proposição, o mundo imaginado por Haraway é composto por redes entrelaçadas entre homens e máquinas, "complexos híbridos de carne e metal que jogam conceitos como 'natural' e 'artificial' para a lata do lixo. Essas redes híbridas são os ciborgues e eles não se limitam a estar à nossa volta - eles nos incorporam” (HARAWAY, 2013, p. 24).

Para Haraway (2013) não há nada de neutro na tecnologia, estamos dentro dela e ela está em nós, pois vivemos em um mundo de conexões e é primordial saber quem é feito e desfeito, o ciborgue não separa o homem das outras espécies, mas sim acopla-o radicalmente.

Paula Sibilia (2002, p. 19) soma aos ciborgues o conceito de corpos pós-orgânicos e acrescenta, que:

os organismos contemporâneos transformaram-se em corpos ligados, ávidos, antenados, ansiosos, sintonizados - e, também, sem dúvida, úteis. Corpos acoplados à tecnologia digital, estimulados e aparelhados por um instrumental sempre atualizado de microdispositivos não-orgânicos.

Tal concepção envolve as diversas tecnologias criadas para potencializar o ser e fazer humano, desde os acessórios pessoais como óculos, relógio e pulseiras até biochips ou wetchips (chips úmidos) ${ }^{5}$ (SIBILIA, 2002 p. 80), que funcionam como gadgets a serviço de uma sociedade que parece não temer unir-se ao silício, assim o devir da humanidade é um devir ciborgue (LEMOS, 2013).

Desde a criação de jogos eletrônicos até a criação de um perfil no Facebook, o trabalho e uso da imagem digital presentifica-se cotidianamente, convence-se qualquer pessoa a crer no que está sendo "visto" no labor intenso do detalhe que simula, modela, tinge, virtualiza ambientes e perfis móveis.

Nesse novo regime do visível, por meio do qual "somos nômades em nossas próprias casas, capturamos imagens, muitas vezes sem modelo, sem fundo, cópias de cópias, no cruzamento de inúmeras significações" (SARDELICH, 2006, p. 452) é necessária uma nova epistemologia, uma visualidade outra que nos possibilite a compreensão dessas realidades e das representações com criticidade e reflexão sobre nós.

"Cada nova tecnologia da imagem nos obriga a repensar o estatuto próprio do conhecimento" (SANTAELLA, 2006, p. 173), as tecnologias da comunicação e informação apenas flutuam e seguem o curso das transmutações contemporâneas, modificando as identidades, a comunicação, a cultura e as formas de ensinar e aprender, tornando imperativo que a educação passe a pensar e aja a fim de acompanhar as realidades que emergem desse novo e errático estar no mundo.

\section{A IMAGEM DIGITAL COMO OBJETO DE ESTUDO: UM RELATO DE EXPERIÊNCIA}

O ser humano sempre busca maneiras diversificadas de se comunicar, transmitir suas emoções e se fazer entender. Com a capacidade de comunicação por meio da linguagem oral e escrita, dife-

5 É um tipo de processador cuja composição é feita de circuitos eletrônicos e organismos vivos (SIBILIA, 2002). 
renciando-se dos demais animais, o homem entrelaça os códigos de informação pelas mais variadas formas de sons e textos.

Atrelada a essa capacidade humana e permeada por significações vastas, a imagem também se desdobra como um elemento constitutivo e elementar das percepções humanas, dizendo e desdizendo sobre algo, penetrando por espaços voláteis de interpretações e originando novos significados e significâncias todo o tempo.

Para Santaella, “o indiscutível domínio da imagem deve-se ao fato de que a revolução tecnológica tem colocado um enorme aparato a serviço da visão, de modo que não se pode negar que o século XX foi o século de triunfo da tecnovisão" (SANTAELLA, 2007, p. 259) e o século XX coloca em foco a soberania do efêmero fotográfico. Contudo, o simples fato de estarmos rodeados de figuras, gráficos, fotografias, outdoors, não potencializa uma imersão nos vários aspectos de representatividade que a imagem pode oferecer.

Diante dessa perspectiva, a cultura visual se desponta como um enlace entre a busca de tentar compreender a imagem não somente por leituras meramente descritivas, mas como essa imagem reflete na composição da vida sociocultural e política contemporânea.

Mirzoeff (apud SARDELICH, 2006, p. 461) enfatiza que a cultura visual é uma “tática para estudar a genealogia, a definição e as funções da vida cotidiana pós-moderna a partir da perspectiva do consumidor, mais que do produtor”. Isso porque, como cita o autor, cultura visual não é uma "disciplina acadêmica”, está envolvida com o cotidiano e se faz presente nas mais simples representações humanas.

Por meio da perspectiva de cultura visual apresentada por Mirzoeff, percebemos que na contemporaneidade este campo de estudo é móvel, como afirma Hernandez (apud SARDELICH, 2006), uma vez que a imagem nos dias hoje se obsoleta muito rapidamente. Com isso, "não há receptores nem leitores, mas sim construtores e intérpretes, na medida em que a aproximação não é passiva nem dependente, mas sim interativa e condizente com as experiências que cada sujeito vive no seu dia-a-dia" (SARDELICH, 2006, p. 466).

Com a facilidade de acesso a recursos digitais disponíveis tanto em computadores quanto em smartphones e tablets, a manipulação imagens (estáticas ou não) deixou de ser uma especialidade para os profissionais. Softwares simples e intuitivos permitem, hoje em dia, que as pessoas criem conteúdos antes restritos a um grupo pequeno de pessoas que se dedicavam a esse trabalho, visto que era um tipo de atividade que requeria tempo e técnica para manipular os programas complexos de edição, "isso faz delas imagens fluidas, soltas, viajantes, migrando de um ponto físico a outro com a leveza do ar" (SANTAELLA, 2007, p. 386).

Os espaços formais de aprendizagem também se configuram como lugares de representações da cultura contemporânea na qual vivemos. A manipulação e reflexão acerca das imagens digitais nos processos de aprendizagem trazem à tona outras formas de percepção de mundo e caminhos variados que contribuem para aprendizagem. Sendo assim, utilizar esse recurso em sala de aula se faz de extrema relevância para oferecermos caminhos outros na manipulação do conhecimento que estejam intimamente ligados às ações cotidianas de quem vive na era digital. 
Em pesquisa qualitativa realizada no Programa de Pós-Graduação em Educação e Diversidade (PPED), pelo Mestrado Profissional em Educação e Diversidade, da Universidade do Estado da Bahia (UNEB), propomos, como pesquisa participante, uma intervenção que ocorreu entre 29 de agosto a 11 de outubro de 2015. Essa intervenção (duração de 80 horas), composta por Oficinas Temáticas, ocorreu no Colégio Estadual de Serrolândia, Bahia, Brasil, com um número de sete professores de língua inglesa, da rede pública e privada de ensino da cidade Serrolândia, Bahia, Brasil.

Trouxemos como concepção pedagógica a Aprendizagem Colaborativa (AC) (DILLENBOURG, 1999) e a pesquisa focava em investigar o desenvolvimento da AC a partir das atividades propostas nas Oficinas Temáticas por meio de recursos digitais variados.

O objeto de estudo foi a imagem digital. Foi possível explorar de forma minuciosa esse conteúdo que possui algumas ramificações, perpassando por fotografias, vídeos, animações, dentre outros recursos. Para tanto, discutimos questões que se relacionavam diretamente com esse objeto, tais como: $A$ Imagem Digital e seus caminhos de apropriação da informação - Fotografia; Merchandising e Marketing na internet: a imagem que veicula poder - Vídeo; Produção colaborativa de Imagem Digital em Movimento - Animação (Comic Strips). Por meio da análise crítica de imagens digitais conectadas às mais diversificadas fontes de transmissão e recepção, discutimos como era possível torná-las mecanismos de aprendizagem.

Observamos a aplicabilidade da aprendizagem colaborativa por meio dos trabalhos desenvolvidos por cada grupo, onde foi possível perceber o interesse ainda maior para a autorreflexão e para o uso da fotografia (e outros desdobramentos da imagem digital) em sala de aula, não como um recurso apenas, mas como um meio de aprimoramento do conhecimento.

Susan Sontag (2004), em seu livro Sobre Fotografia, traz questões bastantes pertinentes acerca das veredas e percursos por onde transita a fotografia e de que modo ela é percebida na sociedade. Sontag afirma que a fotografia não é apenas uma imagem, mas sim uma interpretação do real, algo decalcado, um vestígio do real. Dessa forma, não só utilizamos a fotografia nos dias de hoje como representação, mas como uma interpretação, recriação do real ou ainda um "recorte da realidade visível capturada pelo clique" (SANTAELLA, 2007, p. 394).

Na primeira oficina, levantamos discussões sobre redes sociais, cibercultura, simulacros, selfies, ubiquidade, identidades, perfis, nativos digitais, dentre outros conceitos. Essas palavras-chave possibilitaram uma reflexão quanto à função da fotografia digital vinculada às concepções de representatividade e interpretação na era digital.

Ao refletirmos sobre esses pontos, pudemos ainda perceber como tem sido o perfil de nosso estudante e quais caminhos viáveis podem ser trilhados para compreendermos melhor a escola como um espaço que tenha uma relação mais próxima com os anseios da sociedade e, mais especificamente, com a realidade na qual vive o nosso discente.

Já no segundo encontro, propomos às equipes atividades como a produção e a colaboração, evidenciando as capacidades individuais e somatizando as capacidades do grupo, visto que, como recurso de produção nesse bloco, tínhamos o vídeo. Martins (2003) nos apresenta as imagens compartilhadas hoje em dia vinculadas às disseminações de poder, enfatizando que não é imagem em si que é o poder, mas é por ela que se instaura a manipulação e imposição de valores. 
A imagem sob esse ponto de vista é manipulada e apresentada como veículo condutor para a propagação de poder, compreendido aqui sob várias perspectivas como a persuasão para a venda de um produto, a distribuição de "santinhos" em propagandas políticas, as imposições de valores particulares nos jornais e nas emissoras de rádio e de TV.

A partir desse mecanismo de condução desses poderes - e de tantos outros - a imagem, hoje ainda mais especificamente a digital, se consolidou, em muitos casos, como um produto fabricado, por meio das tecnologias digitais, para alcançar as mais variadas classes sociais e assim disseminar valores particulares. A imagem digital no século XXI tem plasticidade, mistura sons, letras, formas diversas, tem natureza nômade, volátil, ubíqua, transcende espaços, tempos e provoca consideráveis transformações na cultura contemporânea.

As tecnologias digitais da informação e da comunicação seriam como a máquina, a imagem digital como um dos produtos e o lucro seria como a consolidação do poder. Martins (2003, p. 7) salienta que

Tenho vindo a acentuar o poder dos dispositivos tecnológicos de imagens: eles aparelham-nos esteticamente, reorganizando a nossa experiência em torno da nossa subjectividade e emotividade, modelam em nós uma sensibilidade artificial, uma sensibilidade que eu disse ser puxada à manivela, uma vez que esses dispositivos tecnológicos funcionam em nós como próteses de produção de emoções, como maquinetas que produzem e administram afectos. Há, todavia, um aspecto sobre o poder das imagens, a que já aludi, que não pode ser iludido: a imagem tecnológica tem poder, mas não é o poder; por muito tentada que seja [...], a imagem tecnológica apenas representa o poder e o simboliza.

Trouxemos esse tema para a segunda Oficina Temática para refletirmos como as imagens digitais carregam mensagens subliminares que nem sempre são assimiladas em um primeiro momento e que, muitas vezes, nós, como educadores, compartilhamos e tomamos esse material como um recurso didático em nossas salas de aula. Com a primazia do excesso das imagens digitais, a percepção de registro entre o que é especial e trivial acaba por perder a importância, dada a celeridade com que as imagens se sobrepõem fluidamente em nosso cotidiano.

Essa visão não desvale o trabalho com vídeos de internet e outros conteúdos, porém a criação, produção e editoração do próprio conteúdo de vídeo na sala de aula ampliam as possibilidades quanto ao aprofundamento do assunto a ser abordado e proporciona que os estudantes, juntamente com 0 professor, experimentem, construam, colaborem e compartilhem a composição de produtos.

No terceiro encontro, discutimos o texto de Juliana Carvalho (2009): Trabalhando com Quadrinhos na Sala de Aula, percebendo que, ao final, havia propostas de trabalho para determinadas disciplinas, como Língua Portuguesa, Educação Artística, Matemática, História, Geografia e Ciências. Os quadrinhos, assim com as charges e gifs, se tornaram veículos de aprendizagem, uma vez que usam a reflexão a partir da análise crítica das imagens e dos textos verbais que os compõem.

A imagem digital, nessas atividades, se instaurou como elemento de análise e, por conseguinte, desvelou aspectos da cultura visual a partir dos valores implícitos contidos nos materiais analisados e produzidos. Desse modo, os professores-cursistas puderam perceber a imagem não apenas por seu caráter re- 
cordativo, mas também formas de concepção e disseminação de valores que dizem sobre um determinado grupo, pois as imagens digitais "falam ideologicamente, abrindo novos espaços, novas interconexões de maneira mais descentralizada, produzindo novos regimes do sentir e do saber” (GOMES; SILVA, 2014, p. 3).

Foi possível perceber que os processos de análise e produtivos com imagem digital, em suas mais variadas ramificações, surtiram efeitos positivos, visto que percebemos as inúmeras possibilidades de trabalhar com esse material em sala de aula, tanto sob o aspecto de construção de material didático, como também pela percepção da análise das imagens veiculadas no ciberespaço.

Assim, o trabalho com imagens digitais pode proporcionar um pensar novo sobre o mundo e quem o cerca, carregado de sentido, posicionamento cultural, social, ideológico e político, o que oportuniza interconexões diversas, descentralizadas e produz regimes singulares do saber e do sentir.

\section{CONSIDERAÇÕES FINAIS}

Diante do exposto, o uso da imagem pela sociedade e, sobretudo pela escola, necessita de um olhar mais analítico, já que ela está presente nos mais variados suportes - impressos ou virtuais, favorecendo a aprendizagem por “uma ação social do olhar" (GOMES; SILVA, 2013). 0 trabalho com o texto imagético em sala de aula precisa ser feito na perspectiva de formar um sujeito receptivo, ativo e crítico, preparado para intervir na sociedade a partir do que aprende dentro e fora da escola, visto que a imagem possibilita diferentes interpretações e análises, ainda que o ambiente da sala de aula pode configurar-se como um espaço instigador e envolvente, para problematizar questões cotidianas que representam o seu eu e o meio social em que os alunos estão envolvidos.

Nos trabalhos desenvolvidos na intervenção, foi possível perceber as significativas ramificações interpretativas que podem surgir a partir do uso crítico da imagem no contexto educacional e, para além disso, os professores-cursistas compreenderam a importância desse recurso em sua prática pedagógica, vinculado aos dispositivos eletrônicos digitais existentes hoje que o tornam ainda mais presente e mutável em nosso dia a dia, reinventado formas, cores, histórias e percepções sobre o mundo e sobre as representações do real que as imagens digitais são capazes de promover.

\section{REFERÊNCIAS}

AGUIAR, Kátia Fonseca. Fotografia digital: hibridações e fronteiras. FAFICH: UFMG, 2006.

Disponível em: http://docplayer.com.br/23663432-Fotografia-digital-hibridacoes-e-fronteiras.html. Acessdo em: 6 mar. 2017.

CARVALO, Juliana. Trabalho com quadrinhos em sala de aula. Disponível em: http://www. educacaopublica.rj.gov.br/suavoz/0116.html. Acessdo em: 6 abr. 2016.

CATALÀ DOMENÈCH, Josep M. La imagen interfaz: representación audiovisual y conocimiento en la era de la complejidad. Bilbao: Universidad del País Vasco, 2010. 
DILLENBOURG, P. What do you mean by collaborative learning? In: DILLENBOURG, P. (Ed.).

Collaborative-learning: Cognitive and Computational Approaches. Oxford: Elsevier, 1999. p. 1-19.

GOMES, Antenor Rita; SILVA, Núbia Oliveira da. Imagem e conhecimento: sentidos moventes, emergências e aprendizagem. REU, Sorocaba-SP, v. 39, n. 2, p. 451-461, dez. 2013.

GOMES, Antenor Rita; SILVA, Núbia Oliveira da. O imagético, a multimodalidade e os hipertextos: novas interfaces da comunicação no facebook. Hipertextus Revista Digital, v. 12, jul. 2014.

HARAWAY, Donna J. Manifesto ciborgue: ciência, tecnologia e feminismo - socialista no final do século XX. [A. do livro] SILVA, Tomaz Tadeu (Org.). Antropologia do ciborgue: as vertigens do póshumano. Belo Horizonte: Autêntica, 2013. p. 126.

LEMOS, André. Cibercultura: tecnologia e vida social na cultura contemporânea. 6. ed. Porto Alegre: Sulina, 2013.

LÉVY, Pierre. 0 que é o virtual. Tradução de Paulo Neves. São Paulo. Ed. 34, 1996.

LÈVY, Pierre. A inteligência coletiva: por uma antropologia do ciberespaço. 9. ed. São Paulo: Loyola, 2014.

MARTINS, M. L. O poder das imagens e as imagens do poder. In: A Tirania da Imagem. Cadernos do ISTA, n. 15, p.127-134, Lisboa: Instituto São Tomás de Aquino, 2003.

QUÉAU, Phillipe. O tempo virtual. In: PARENTE, André (Org.). Imagem máquina. Rio de Janeiro: Editora 34, 2003. p. 91-99.

SANTAELLA, Lucia. Linguagens líquidas na era da mobilidade. São Paulo: Paulus, 2007.

SANTAELLA, Lucia; NÖTH, Winfried. Imagem: cognição, semiótica, mídia. São Paulo: Iluminuras, 1998.

SANTAELLA, Lucia. 0 que é semiótica. São Paulo: Editora Brasiliense, 2006.

SARDELICH. Maria Emília. Leitura de imagens, cultura visual e prática educativa. Cadernos de Pesquisa, v. 36, n. 128, p. 451-472, maio/ago. 2006. Disponível em: http://www.scielo.br/pdf/cp/ v36n128/v36n128a09.pdf. Acesso em: 10 de agosto 2017

SONTAG, Susan. Sobre fotografia. Trad. Rubens Figueiredo. São Paulo: Companhia das Letras, 2004. 
1 Possui graduação em Enfermagem pela Universidade Federal de Alagoas (2006), Especialização em Enfermagem do Trabalho pela Universidade Estadual de Ciências da Saúde de Alagoas e mestrado em Ensino na Saúde pela Faculdade de Medicina da Universidade Federal de Alagoas (2014). Doutorado em andamento em Saúde Pública na Universidade de São Paulo. Atualmente é Professora adjunta I e membro titular do Colegiado do Curso de Enfermagem do Centro Universitário Tiradentes. Docente e membro do Núcleo Docente Estruturante do curso de Enfermagem da Universidade Estadual de Ciências da Saúde de Alagoas. Editora Executiva do Caderno de Graduação - UNIT/ AL - Ciências Biológicas e da Saúde. Email para contato: apaularebelo@hotmail.com

2 fessora Associada IV da Faculdade de Medicina da Universidade Federal de Alagoas. Doutorado em Saúde da Criança e do Adolescente (USP/Faculdade de Medicina de Ribeirão Preto/SP, 2003); Mestrado em Saúde da Criança pela UFAL/ UFS (1995); . Residência Médica em Pediatria (1980), Residência Médica em Nefrologia pediátrica pela Faculdade de Ciencias Médicas da Santa Casa de São Paulo ( 1982); Especialista em Educação das Profissões de Saúde (UFC/ FAIMER Br, 2009);E-mail: camposdelisboa@gmail.com

3 Doutor em Ciências Morfológicas; Professor adjunto IV da Universidade Federal de Alagoas - UFAL.

E-mail: rrodarte@ig.com.br

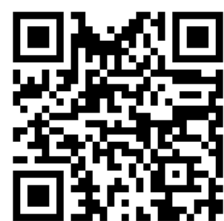

A autenticidade desse artigo pode ser conferida no site https://periodicos. set.edu.br

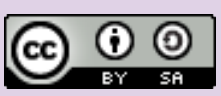

Este artigo é licenciado na modalidade acesso abertosob a Atribuição-Compartilhalgual CC BY-SA

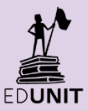

